\title{
Levantamento etnobotânico, químico e farmacológico de espécies de Apocynaceae Juss. ocorrentes no Brasil
}

\author{
SANTOS, A.C.B. ${ }^{1 *}$; SILVA, M.A.P. ${ }^{1 ;}$ SANTOS, M.A.F.'; LEITE, T.R. ${ }^{1}$ \\ ${ }^{1}$ Programa de Pós-graduação em Bioprospecção Molecular, Universidade Regional do Cariri - URCA, Rua Cel. \\ Antônio Luis, 1161, Pimenta, CEP: 63100-000, Crato, Ceará, Brasil *carlitobio@yahoo.com.br
}

\begin{abstract}
RESUMO: Este trabalho visou realizar um levantamento bibliográfico dos registros etnobotânicos, químicos e farmacológicos de espécies de Apocynaceae ocorrentes em diversas regiões do Brasil. Foi feito um compilamento dos dados organizados em ordem alfabética de espécies, seguidas do nome popular, categoria de uso, parte usada, forma de uso, atividade farmacológica, composição química e distribuição geográfica. Identificou-se 78 espécies distribuídas em 27 gêneros, onde Hancornia speciosa Gomes foi a mais citada. A categoria de uso medicinal foi a mais representativa com 61 indicações e a casca foi à parte mais utilizada das plantas com 29 citações. Poucos estudos farmacológicos e químicos foram realizados, havendo a necessidade de investimento nessas áreas para comprovações dos usos tradicionais.
\end{abstract}

Palavras-chave: Etnobotânica, Apocynaceae, Brasil.

\begin{abstract}
Ethnobotanical, chemical and pharmacological survey of Apocynaceae Juss. Species occurring in Brazil. This study aimed to perform a bibliographic survey of ethnobotanic, chemical and pharmacological Apocynaceae species occurring in several regions of Brazil. Data were compiled and arranged in alphabetical order of species, followed by their popular name, use category, the part used, use method, pharmacological activity, chemical composition and geographic distribution. We identified 78 species in 27 genera, where Hancornia speciosa Gomes was the most mentioned one. The medicinal use category was the most representative one, with 61 indications, and the bark was the most used part of the plant, with 29 references. Few pharmacological and chemical studies were performed, with the need to invest in these areas to evidence traditional uses.
\end{abstract}

Key words: Ethnobotany, Apocynaceae, Brazil.

\section{INTRODUÇÃO}

A evolução do conhecimento científico sobre as plantas e sua utilização pelo homem têm ocorrido através dos tempos. Civilizações primitivas perceberam a existência de plantas comestíveis e dotadas de toxicidade que, ao serem utilizadas no combate às doenças, revelavam empiricamente seu potencial curativo (Barros, 2008).

Nesse contexto, a etnobotânica surge para compreender o estudo das sociedades humanas e suas interações com as plantas, sejam elas ecológicas, genéticas, evolutivas, simbólicas ou culturais (Fonseca-Kruel \& Peixoto, 2004), resgatando os conhecimentos tradicionais passados de geração em geração e contribuindo para descobertas de novas drogas com princípios ativos para o tratamento de enfermidades.

No entanto, a evidente descaracterização das comunidades tradicionais, acompanhada da destruição de habitats e da inserção de novos elementos culturais, põe em risco um grande acervo de conhecimentos empíricos e um patrimônio genético de valor inestimável para as futuras gerações (Pires et al., 2009).

Desse modo, estudos etnobotânicos são importantes e se fazem necessários, especialmente no Brasil, uma vez que esse país apresenta a maior diversidade genética vegetal do mundo, contando com mais de 55.000 espécies catalogadas (Nodari \& Guerra, 1999), onde 99,6\% são desconhecidas quimicamente (Gottlieb et al., 1996).

No Brasil, diversos trabalhos etnobotânicos estão disponíveis à comunidade científica, principalmente relacionados às plantas medicinais (Borges \& Peixoto, 2009; Mosca \& Loiola, 2009; Silva

Recebido para publicação em 14/12/2011

Aceito para publicação em 28/11/2012

Rev. Bras. PI. Med., Campinas, v.15, n.3, p.442-458, 2013. 
\& Proença, 2008; Agra et al., 2007a; Albuquerque et al., 2007; Maioli-Azevedo \& Fonseca-Kruel, 2007; Azevedo \& Silva, 2006; Morais et al., 2005; Guarim-Neto \& Morais, 2003; Nunes et al., 2003; Amorozo, 2002; Ritter et al., 2002, Guarim-Neto et al., 2000). Porém, esses estudos abordam somente comunidades indígenas, ribeirinhas ou áreas específicas de uma dada localidade, não se detendo em estudar isoladamente uma família botânica ocorrente em diversas regiões, exceto o trabalho de Guarim-Neto et al. (2000), onde registram o conhecimento etnobotânico sobre as espécies de Sapindaceae Jussieu no Brasil.

Nesse sentido, as espécies da família Apocynaceae registraram grande importância nos estudos etnobotânicos, porém, a relevância desta família ainda não foi devidamente estudada, especialmente por ser um grupo de ampla distribuição e ter espécies com usos diferenciados. Dessa forma, o presente trabalho teve por objetivo compilar os estudos etnobotânicos referentes às espécies de Apocynaceae citadas na literatura científica, no período de 1995 a 2010, fornecendo informações acerca da distribuição geográfica das espécies, aspectos etnobotânicos, composição química e estudos farmacológicos.

\section{MATERIAL E MÉTODOS}

A família Apocynaceae Juss. destaca-se por possuir uma riqueza de espécies que são utilizadas principalmente como ornamentais, medicinais e na construção civil. Com aproximadamente 355 gêneros e 3700 espécies, esta família apresentase amplamente e predominantemente distribuída nas regiões tropicais e subtropicais, com poucos gêneros ocorrendo em regiões temperadas (Judd et al., 2009). No Brasil, são encontrados cerca de 95 gêneros e 850 espécies (Souza \& Lorenzi, 2008), que ocorrem em diversas formações, como as Florestas Pluviais Amazônica, Atlântica e de Tabuleiro, Floresta Seca, Restinga, Cerrado e Caatinga (Quinet \& Andreata, 2005).

O estudo foi baseado em um levantamento bibliográfico referente a 112 trabalhos publicados nos últimos 15 anos (1995-2010) sobre os estudos etnobotânicos, químicos e farmacológicos das espécies de Apocynaceae nas diversas regiões do Brasil.

Os artigos científicos que serviram de bases para este trabalho foram extraídos de revistas científicas de âmbito nacional (Acta Botanica Brasilica; Agropecuária Científica no Semi-Árido; Caminhos de Geografia; Ciência Hoje; Ciência e Agrotecnologia; Diálogos; Iheringia; Interciência; Oecologia Brasiliensis; Pesquisas, Botânica; Revista Brasileira de Biociências; Revista Brasileira de Farmacognosia; Revista Caatinga; Revista Saúde.com; Química Nova) e internacional (Acta Farmaceutica Bonaerense, American Journal of Botany; Brazilian Journal of Medical and Biological Research; Brazilian Journal of Pharmacognosy; Chemical \& Pharmaceutical Bulletin; Current Science; Environmental Monitoring and Assessment; Environ Monit Assess; Food Chemistry; Fitoterapia; Genetica; Journal of Arid Environments, Journal of Ethnopharmacology; Memórias do Instituto Oswaldo Cruz; Phytochemistry; Phytomedicine; Journal of Medical Biography; Planta Medica; Plant Cell Tiss Org; Texas Heart Institute Journal), com as seguintes palavras-chave: Apocynaceae, Etnobotânica, Plantas Medicinais, Brasil, Composição Química, Fitoquímica, Atividade Biológica e farmacológica.

As espécies foram enquadradas, segundo a sua utilidade, nas seguintes categorias de uso: Ornamental, Medicinal, Madeireira, Alimentícia, Ritual, Tecnológica, Construção Civil, Combustível, Tóxica e Outros. As plantas com fins ornamentais e madeireira foram consideradas como Planta inteira $(\mathrm{Pi})$ e Caule $(\mathrm{Ca})$ respectivamente no critério de parte utilizada.

Para revisão dos nomes científicos, sinonímias e distribuição geográfica das espécies citadas foram utilizados os seguintes banco de dados: Lista de espécies da flora do Brasil 2010 (http://floradobrasil.jbrj.gov.br/2010/); Missouri Botanical Garden (http://mobot.org/) e Tropicos (http://www.tropicos.org/).

\section{RESULTADOS E DISCUSSÃO}

No levantamento etnobotânico da família Apocynaceae, foram identificadas 78 espécies distribuídas em 27 gêneros, sendo Hancornia speciosa Gomes (Mangabeira), Aspidosperma pyrifolium Mart. (Pereiro-preto) e Catharanthus roseus (L.) Don (Boa-noite), as espécies mais citadas na literatura, com 23, 17 e 12 registros respectivamente.

Dentre os gêneros com maior número de espécies estão Aspidosperma com 20 registros, seguidas de Himatanthus (nove) e Rauvolfia (seis). Das espécies identificadas, sete táxons (Aspidosperma sp1 (Pitiá), A. sp2 (Pitiá-mandioca), Ervatamia sp1 (Jasmim-cambraia), E. sp2 (Jasmimpera), Himatanthus sp. (Janaguba), Plumeria sp. (Jasmim-vapor), Tabernaemontana sp. (Jasmimbravo)) foram identificados apenas a nível de gênero.

Dados relacionados à etnobotânica citam diferentes usos para as espécies de Apocynaceae, onde foram agrupadas em dez categorias distintas, sendo 61 indicações medicinais, 22 ornamentais, 13 madeireira, dez construção civil, oito tecnológica,

Rev. Bras. PI. Med., Campinas, v.15, n.3, p.442-458, 2013. 
sete tóxica, três ritualista, três "outros usos", uma alimentícia e uma combustível, tendo a maioria das espécies citadas em múltiplas categorias de uso.

A parte da planta mais usada foi à casca com 29 citações, seguidas da planta inteira (26), raiz (20), folha (19), caule (19) e látex (16). As demais partes variaram de um a nove indicações.

Algumas espécies possuem importância econômica e/ou medicinal, devido à presença de metabólitos secundários no látex como, por exemplo, hidrocarbonetos poliisoprénicos (borracha), triterpenos, ácidos graxos, fitoesteróis e alcalóides (Metcalfe \& Chalk, 1950; Yoder \& Mahlberg, 1976).

Para Rizzini \& Mors (1995), a família tem se destacado pela sua ampla utilidade econômica, onde se encontram algumas espécies do gênero Landolphia Beauv. que fornecem látex para a produção de borracha; em outras espécies seu látex é utilizado para o preparo da goma de mascar. $O$ fruto de Hancornia speciosa Müll. Arg. (mangabeira) é utilizado na alimentação, geralmente no preparo de sucos e sorvete.

Os gêneros de Aspidosperma Mart., Geissospermum Allemão e Tabernaemontana L. destacam-se por possuírem espécies fornecedoras de madeira de boa qualidade (Quinet \& Andreata, 2005).

Souza \& Lorenzi (2008) citaram que muitas espécies são cultivadas para fins ornamentais, sendo que diversas delas são tóxicas para o ser humano e, por esta razão, não são apropriadas para o cultivo em determinadas áreas.

Estudos químicos e farmacológicos têm grande importância em levantamento etnobotânicos, pois comprovam os efeitos medicinais e toxicológicos das espécies utilizadas. Dessa forma, diversos trabalhos já foram realizados nesse âmbito, como os estudos de Silva et al. (2004); Baggio et al. (2005); Moza (2005); Almeida et al. (2007); Biavatti et al. (2007); Pereira et al. (2007); Moraes et al. (2008); Nardin et al. (2009) e Santos et al. (2009). Contudo, pouco ainda tem sido estudado frente ao grande número de plantas com diversas potencialidades medicinais.

Desse modo, as informações das plantas e seus usos etnobotânicos estão compilados na Tabela 1, organizada por ordem alfabética de espécies, seguidas pelo nome vulgar, categoria de uso, parte utilizada, formas de uso, composição química, estudos farmacológicos e distribuição geográfica no Brasil.

\section{CONCLUSÃO}

Este estudo é pioneiro em relação ao estudo etnobotânico das espécies de Apocynaceae e mostra a grande importância e diversidade de uso das espécies. Vale salientar que pouco ainda se conhece sobre as propriedades farmacológicas e químicas, onde se faz necessários esforços na investigação dos princípios ativos das plantas medicinais que comprovam as atividades citadas pelas comunidades tradicionais.

\section{AGRADECIMENTOS}

A Fundação Cearense de Apoio ao Desenvolvimento Científico e Tecnológico (FUNCAP) pelo financiamento da pesquisa e a equipe do Herbário Caririense Dárdano de Andrade-Lima (HCDAL) da Universidade Regional do Cariri - URCA pela contribuição nesse manuscrito.

\section{REFERÊNCIA}

AGRA, M.F.; BARACHO, G.S.; BASÍLIO, I.J.D.; NURIT, K.; COELHO, V.P; BARBOSA, D.A. Sinopse da flora medicinal do Cariri Paraibano. Oecologia Brasiliensis, v.11, n.3, p.323-330, 2007a.

AGRA, M.F.; FREITAS, P.F.; BARBOSA-FILHO, J.M. Synopsis of the plants known as medicinal and poisonous in Northeast of Brazil. Brazilian Journal of Pharmacognosy, v.17, n.1, p.114-140, 2007b.

AGRA, M.F.; SILVA, K.N.; BASÍLIO, I.J.L.D.; FREITAS, P.F.; BARBOSA-FILHO, J.M. Survey of medicinal plants used in the region Northeast of Brazil. Brazilian Journal of Pharmacognosy, v.18, n.3, p.472-508, 2008.

ALBUQUERQUE, U.P.; ANDRADE, L.H.C. Conhecimento botânico tradicional e conservação em uma área de caatinga no estado de Pernambuco, Nordeste do Brasil. Acta Botanica Brasilica, v.16, n.3, p.273-285, 2002a.

ALBUQUERQUE, U.P.; ANDRADE, L.H.C. Uso de recursos vegetais da caatinga: o caso do agreste do estado de Pernambuco (Nordeste do Brasil). Interciência, v.27, n.7, p.336-346, 2002b.

ALBUQUERQUE, U.P.; ANDRADE, L.H.C.; CABALLERO, J. Structure and floristics of homegardens in Northeastern Brazil. Journal of Arid Environments, v.62, p.491-506, 2005a.

ALBUQUERQUE, U.P.; ANDRADE, L.H.C.; SILVA, A.C.O. Use of plant resources in a seasonal dry forest (Northeastern Brazil). Acta Botanica Brasilica, v.19, n.1, p.27-38, 2005b.

ALBUQUERQUE, U.P.; MEDEIROS, P.M.; ALMEIDA, A.L.S.; MONTEIRO, J.M.; LINS-NETO, E.M.F.; MELO, J.G.; SANTOS, J.P. Medicinal plants of the caatinga (semi-arid) vegetation of NE Brazil: A quantitative approach. Journal of Ethnopharmacology, v.114, p.325-354, 2007.

ALBUQUERQUE, U.P.; OLIVEIRA, R.F. Is the use-impact on native caatinga species in Brazil reduced by the high species richness of medicinal plants? Journal of Ethnopharmacology, v.113, p.156-170, 2007.

ALMEIDA, C.F.C.B.R.; SILVA, T.C.L.; AMORIM, E.L.C.; MAIA, M.B.S.; ALBUQUERQUE, U.P. Life strategy and chemical composition as predictors of the selection of medicinal plants from the caatinga (Northeast Brazil).

Rev. Bras. PI. Med., Campinas, v.15, n.3, p.442-458, 2013. 


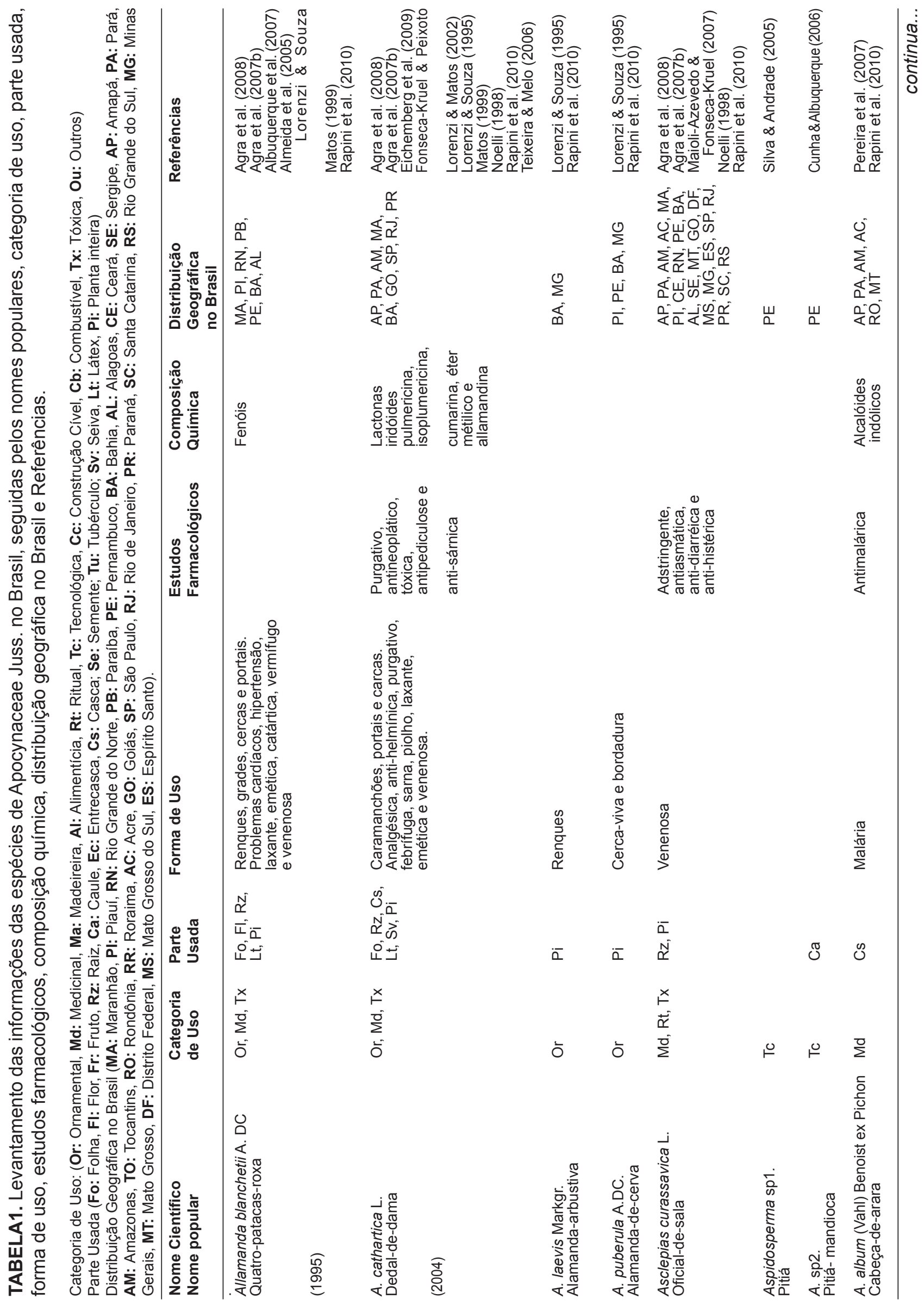

Rev. Bras. PI. Med., Campinas, v.15, n.3, p.442-458, 2013. 


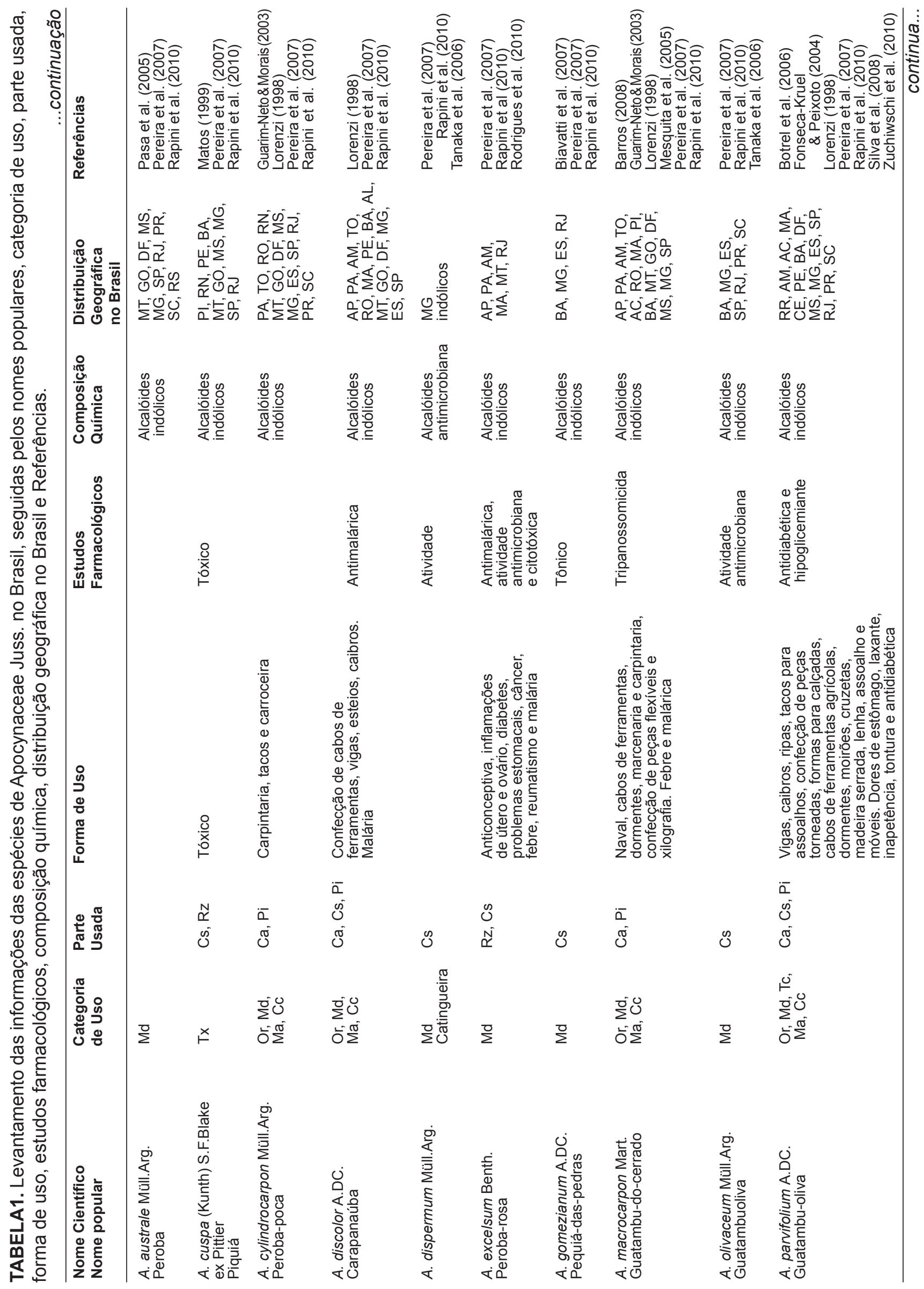

Rev. Bras. PI. Med., Campinas, v.15, n.3, p.442-458, 2013. 


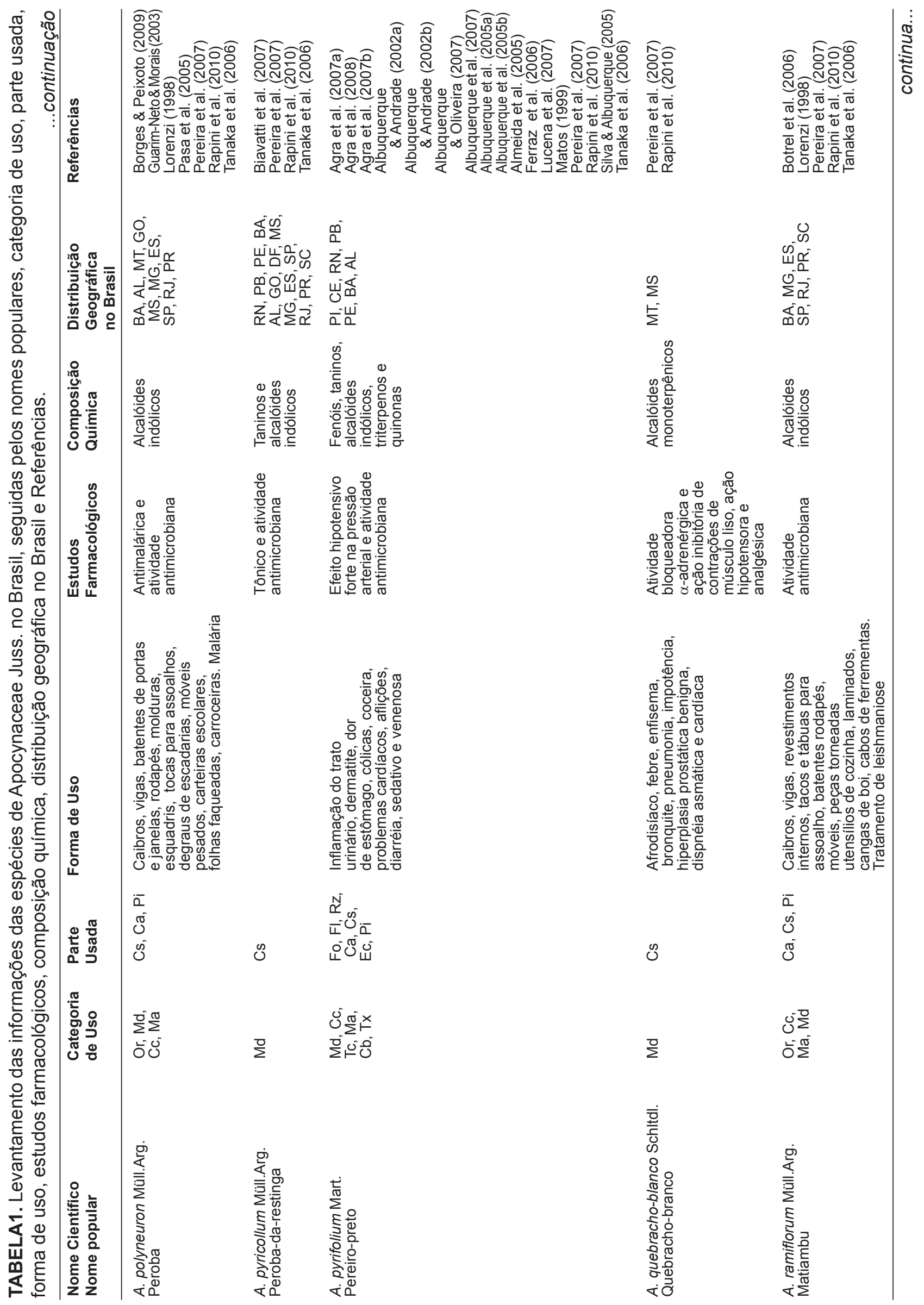

Rev. Bras. PI. Med., Campinas, v.15, n.3, p.442-458, 2013. 


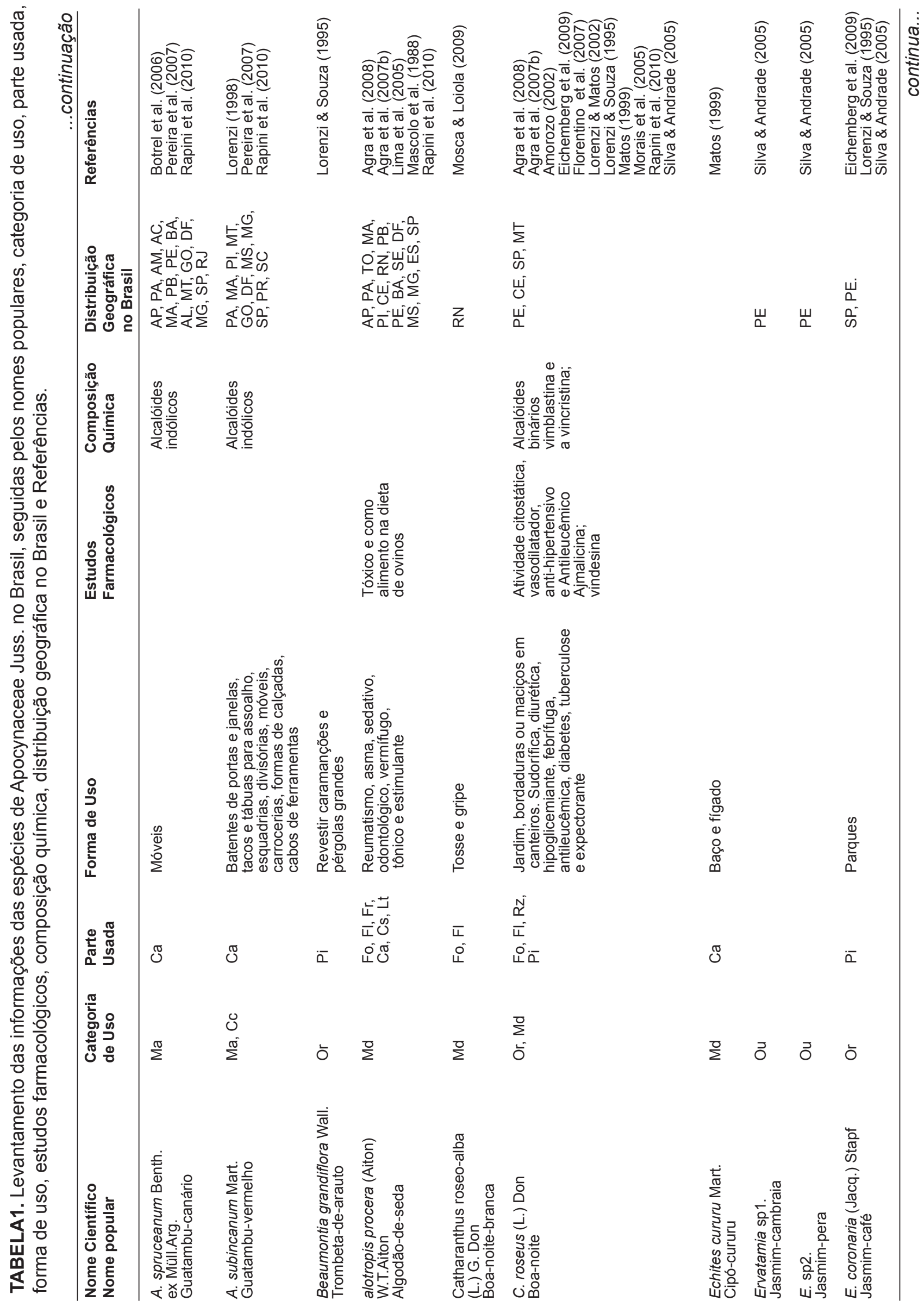

Rev. Bras. PI. Med., Campinas, v.15, n.3, p.442-458, 2013. 


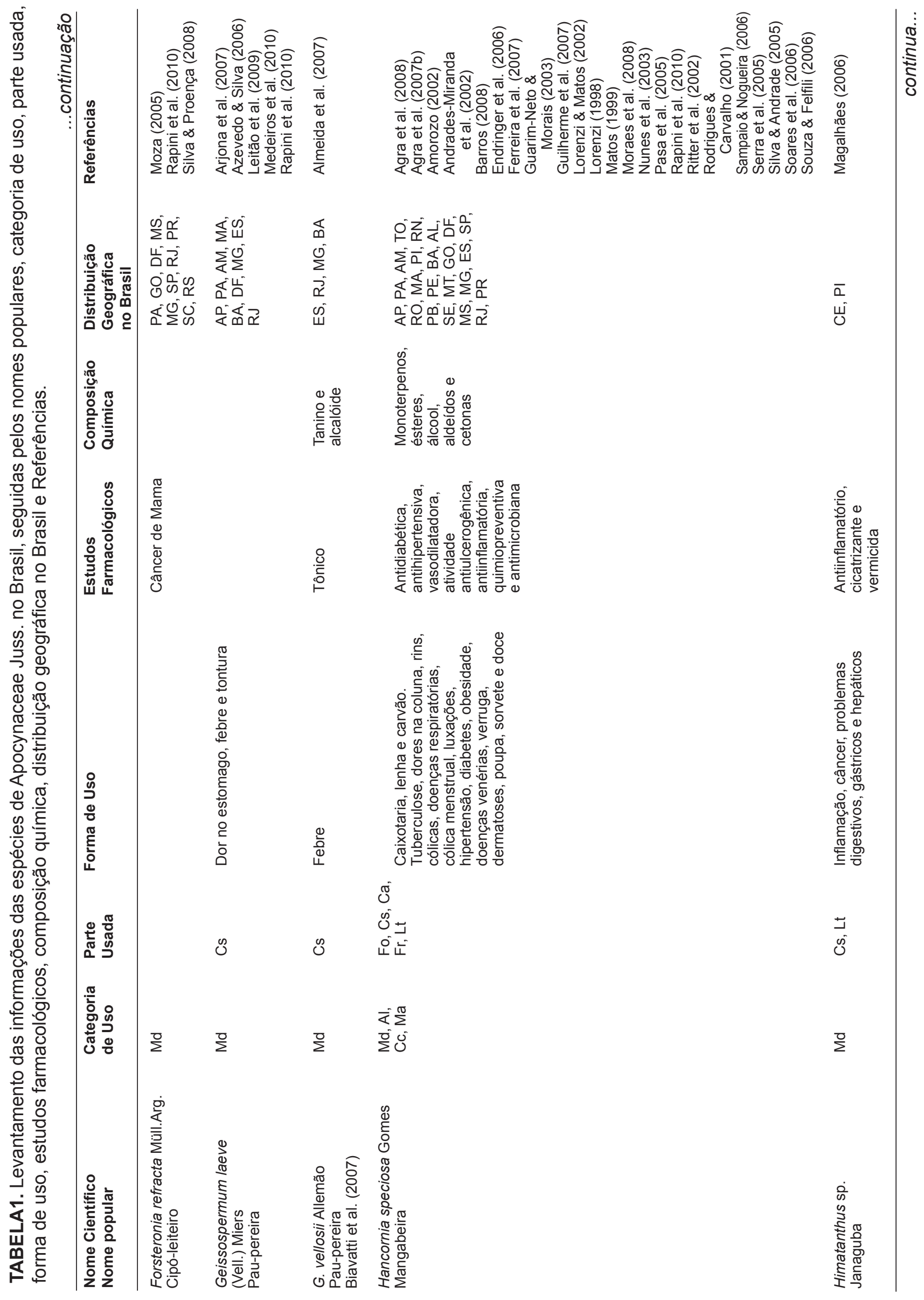

Rev. Bras. PI. Med., Campinas, v.15, n.3, p.442-458, 2013. 


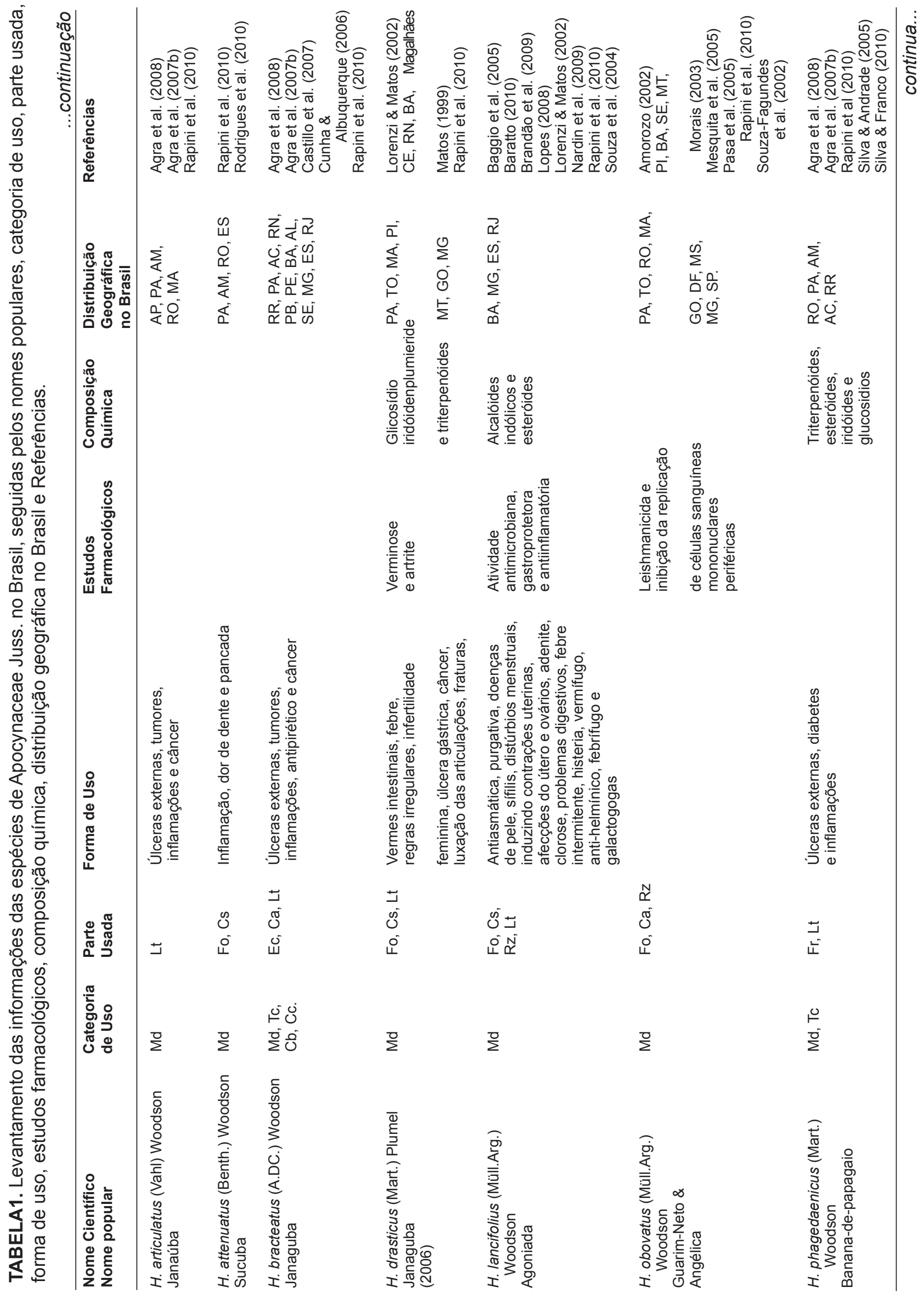

Rev. Bras. PI. Med., Campinas, v.15, n.3, p.442-458, 2013. 


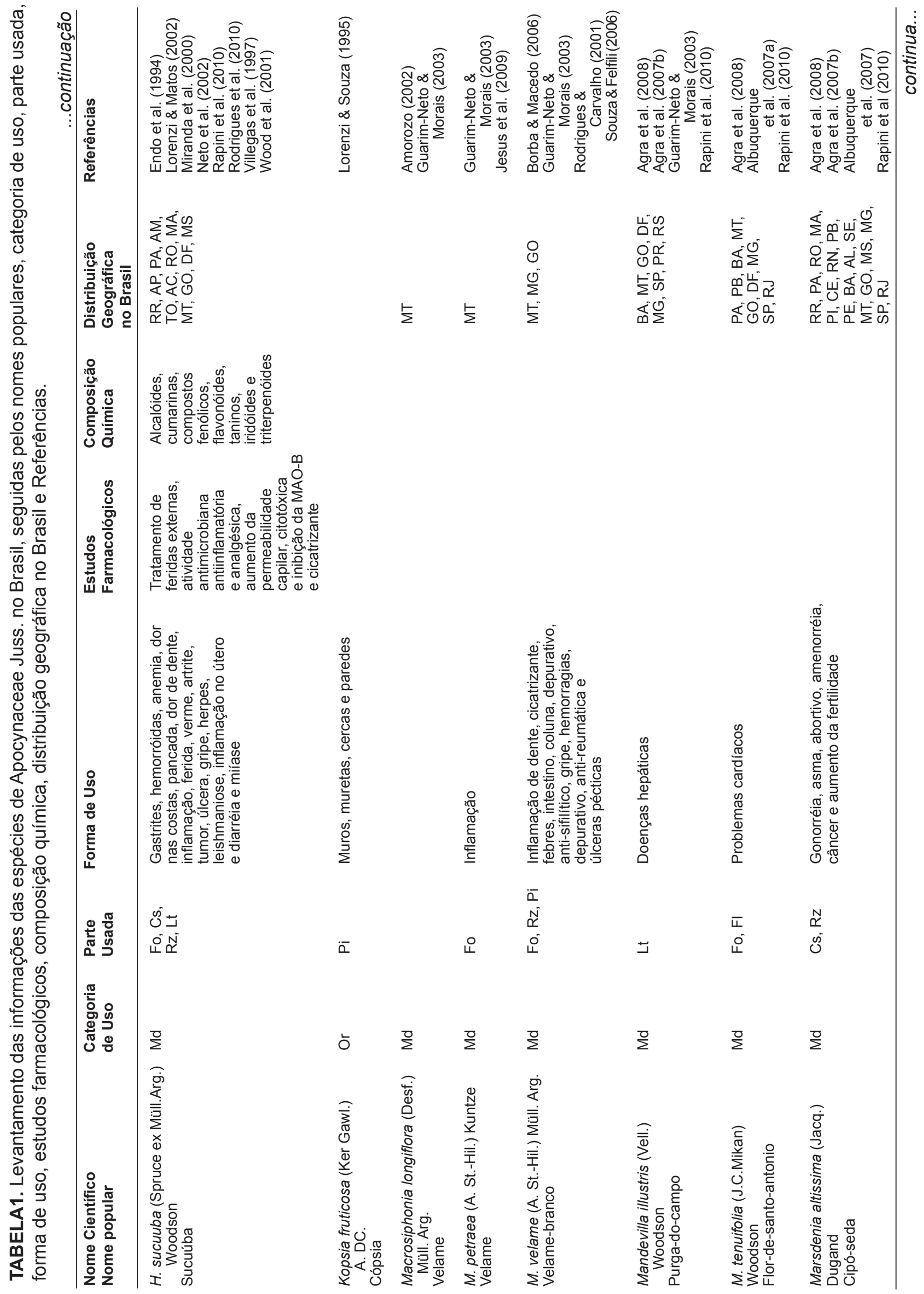

Rev. Bras. PI. Med., Campinas, v.15, n.3, p.442-458, 2013. 


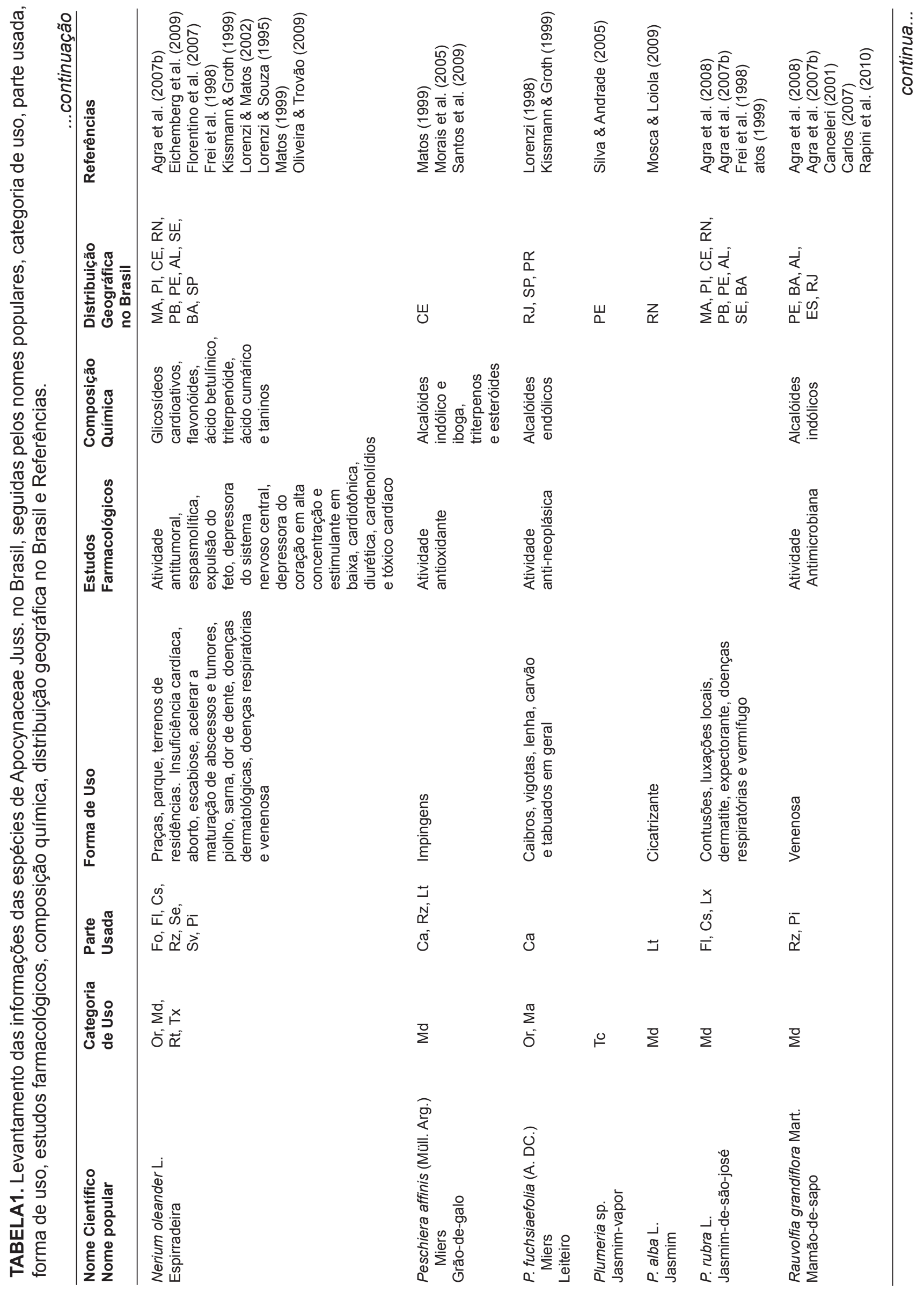

Rev. Bras. Pl. Med., Campinas, v.15, n.3, p.442-458, 2013. 


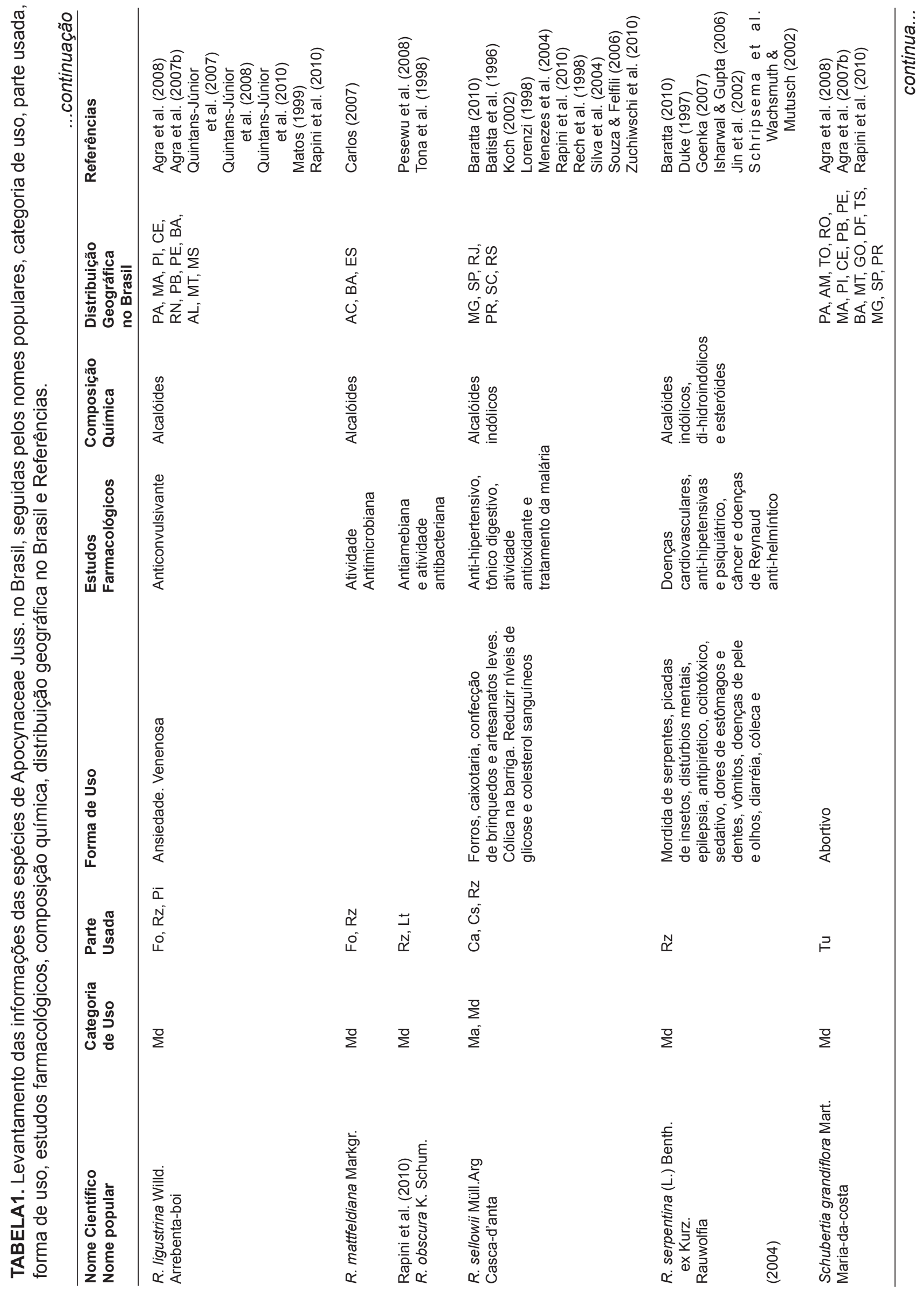

Rev. Bras. PI. Med., Campinas, v.15, n.3, p.442-458, 2013. 


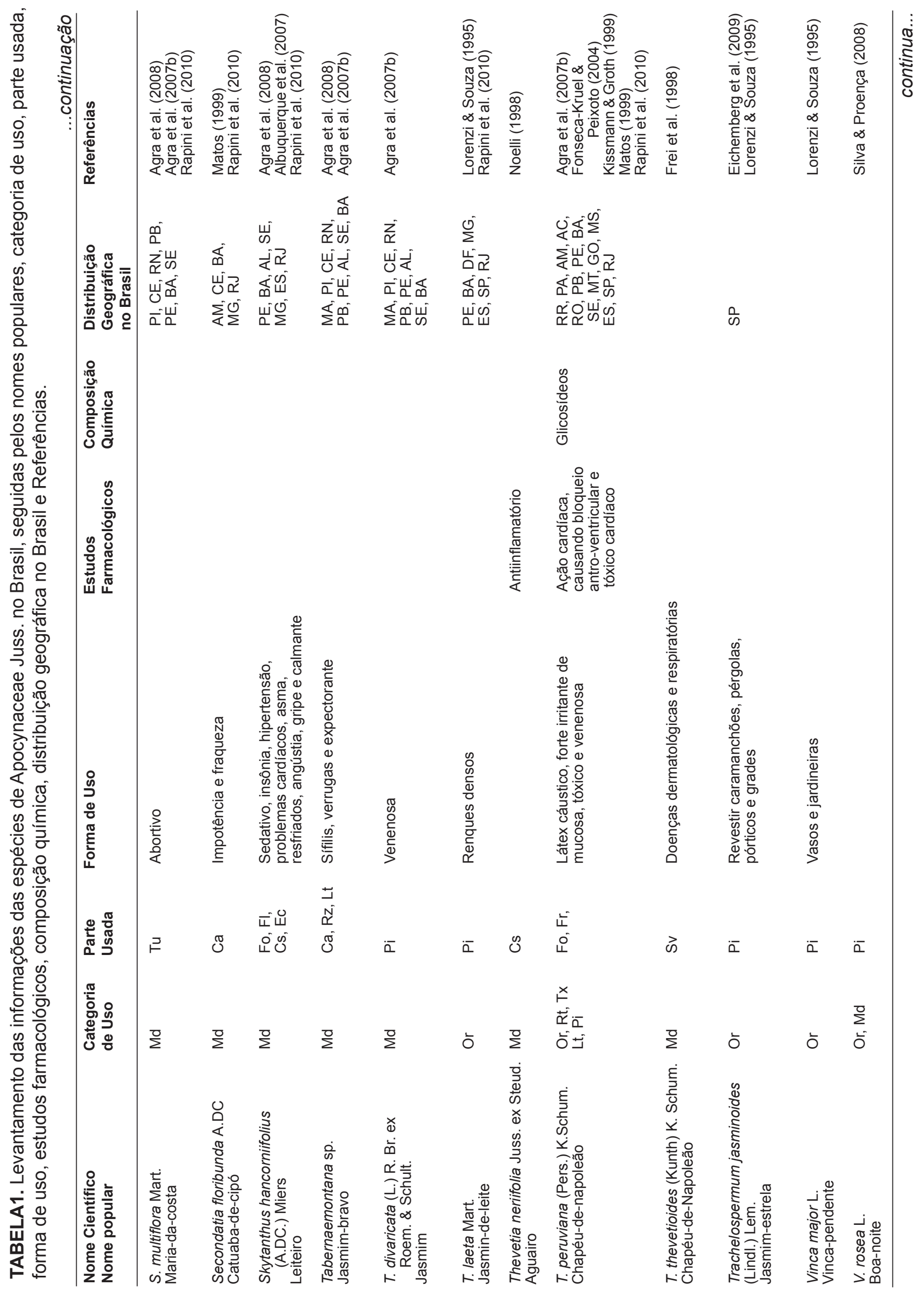

Rev. Bras. PI. Med., Campinas, v.15, n.3, p.442-458, 2013. 
Journal of Arid Environments, v.62, p.127-142, 2005.

ALMEIDA, M.R.; LIMA, J.A.; SANTOS, N.P.; PINTO, A.C. Pereirina: O primeiro alcalóide isolado no Brasil. Ciência Hoje, v.40, n.240, p.26-31, 2007.

AMOROZO, M.C.M. Uso e diversidade de plantas medicinais em Santo Antonio do Leverger, MT, Brasil. Acta Botanica Brasilica, v.16, n.2, p.189-203, 2002.

ANDRADES-MIRANDA, J.; ZANCHIN, N.I.; OLIVEIRA, L.F.; LANGGUTH, A.R.; MATTEVI, M.S. (T2AG3) $n$ telomeric sequence hybridization centric fusion rearrangements in the karyotype of the rodent oryzomys subflavus. Genetica, v.114, n.1, p.11-16, 2002.

ARJONA, F.B.S.; MONTEZUMA, R.C.M.; SILVA, I.M. Aspectos etnobotânicos e biogeografia de espécies medicinais e/ou rituais comercializadas no mercado de Madureira, RJ. Caminhos de Geografia, v.8, n.23, p.41-50, 2007.

AZEVEDO, S.K.S.; SILVA, I.M. Plantas medicinais e de uso religioso comercializadas em mercados e feiras livres no Rio de Janeiro, RJ, Brasil. Acta Botanica Brasilica, v.20, n.1, p.185-194, 2006.

BAGGIO, C.H.; OTOFUJI, G.D.; SOUZA, W.M.; SANTOS, C.A.D.; TORES, L.M.B.; RIECK, L.; MARQUES, M.C.D.; MESIA-VELA, S. Gastroprotective mechanisms of índole alkaloids from Himatanthus lancifolius. Planta Medica, v.71, p.733-738, 2005.

BARATTO, L.C. Estudo químico-analítico e morfoanatômico de espécies medicinais brasileiras da família Apocynaceae: Himatanthus lancifolius (Müll. Arg.) Woodson e Rauvolfia sellowii Müll. Arg. 2010. 157p. Dissertação (Mestrado em Ciências Farmacêuticas) - Universidade Federal do Paraná, Curitiba.

BARROS, I.M.C. Contribuição ao Estudo Químico e Biológico de Hancornia spiciosa Gomes. (Apocynaceae). 2008. 194p. Dissertação (Mestrado em Ciências da Saúde) - Faculdade de Ciências da Saúde, Universidade de Brasília, Brasília

BATISTA, C.V.F. SCRIPSEMA, J.; VERPOORTE, R.; RECH, S.B.; HENRIQUES, A.T. Indole alkaloids from Rauwolfia sellowii. Phytochemistry, v.41, p.969-973, 1996

BIAVATTI, M.W.; MARENSI, V.; LEITE, S.N.; REIS, A. Ethnopharmacognostic survey on botanical compendia for potential cosmeceutic species from Atlantic Forest. Brazilian Journal of Pharmacognosy, v.17, n.4, p.640-653, 2007.

BORBA, A.M.; MACEDO, M. Plantas medicinais usadas para a saúde bucal pela comunidade do bairro Santa Cruz, Chapada dos Guimarães, MT, Brasil. Acta Botanica Brasilica, v.20, n.4, p.771-782, 2006.

BORGES, R.; PEIXOTO, A.L. Conhecimento e uso de plantas em uma comunidade caiçara do litoral sul do Estado do Rio de Janeiro, Brasil. Acta Botanica Brasilica, v.23, n.3, p.769-779. 2009.

BOTREL, R.T.; RODRIGUES, L.A.; GOMES, L.J.; CARVALHO, D.A.; FONTES, M.A.L. Uso da vegetação nativa pela população local no município de Ingaí, MG, Brasil. Acta Botanica Brasilica, v.20, n.1, p.143-156, 2006.

BRANDÃO, M.G.L.; COSENZA, G.P.; GRAEL, C.F.F.; NETTO-JUNIOR, N.L.; MONTE-MÓR, R.L.M. Traditional uses of American plant species from the $1^{\text {st }}$ edition of
Brazilian Official Pharmacopoeia. Revista Brasileira de Farmacognosia, v.19, p.478-487, 2009

CANCELERI, N.M. Alcalóides indólicos de Rauvolfia grandiflora Mart. 2001. 204p. Dissertação (Mestrado) - Universidade Estadual do Norte Fluminense - UENF, Campos dos Goytacazes - RJ.

CARLOS, L.A. Alcaloides de Rauvolfia grandiflora e Rauvolfia mattfeldiana (Apocynaceae). 2007. 200p. Tese (Doutorado) - Centro de Ciências Tecnológicas e Agropecuárias, Universidade Estadual do Norte Fluminense Darcy Ribeiro, Campos dos Goytacazes - RJ.

CASTILLO, D.; AREVALO, J.; HERRERA, F.; RUIZ, C.; ROJAS, R.; RENGIFO, E.; VAISBERG, A. LOCK, O.; LEMESRE, J.L.; GORNITZKA, H.; SAUVAIN, M. Spirolactone iridoids mignt be responsible for the antileishmanial activity of a Peruvian traditional remedly made with Himatanthus sucuuba (Apocynaceae). Journal of Ethnopharmacology, v.112, p.410-414, 2007.

CUNHA, L.V.F.C.; ALBUQUERQUE, U.P. Quantitative ethnobotany in an atlantic forest fragment of Northeastern Brazil - implications to conservation. Environmental Monitoring and Assessment, v.114, p.1-25, 2006.

DUKE, J.A. The green pharmacy: new discoveries in herbal medicines for common diseases and conditions from the nation's foremost authority on healing herbs. Pennsylvania: Rodale Press, 1997.

EICHEMBERG, M.T.; AMOROZO, M.C.M.; MOURA, L.C. Species composition and plant use in old urban homegardens in Rio Claro, Southeast of Brazil. Acta Botanica Brasilica, v.23, n.4, p.1057-1075. 2009.

ENDO, Y.; HAYASHI, H.; SATO, T.; MARUNO, M.; OHTA, T.; NOZOE, S. Confluentic acid and 2'-O-methylperlatolic acid, monoamine oxidase B inhibitors in a brazilian plant, Himatanthus sucuuba. Chemical \& Pharmaceutical Bulletin, v.42, p.1198-1201, 1994.

ENDRINGER, D.C.; KONDRATYUK, T.; RAGA, F.C.; PEZZUTO, J.M. Phytochemical Study of Hancornia speciosa guided by in vitro cancer chemiopreventive assays. In: 47th Annual Meeting of the American Society of Pharmacognosy, 2006, Washington. Abstract book of the 47th Annual Meeting of the American Society of Pharmacognosy, 2006.

FERRAZ, J.S.F.; ALBUQUERQUE, U.P.; MEUNIER, I.M.J. Valor de uso e estrutura da vegetação lenhosa às margens do riacho do Navio, Floresta, PE, Brasil. Acta Botanica Brasilica, v.20, n.1, p.125-134, 2006.

FERREIRA, H.C.; SERRA, C.P.; LEMOS, V.S.; BRAGA, F.C.; CORTES, S.F. Nitric oxide-dependent vasodilatation by ethanolic extract of Hancornia spiciosa via phosphatidylinositol 3-kinase. Journal of Ethnopharmacology, v.109, n.1, p.161-164, 2007

FLORENTINO, A.T.N.; ARAÚJO, E.L.; ALBUQUERQUE, U.P. Contribuição de quintais agroflorestais na conservação de plantas da Caatinga, Município de Caruaru, PE, Brasil. Acta Botanica Brasilica, v.21, n.1, p.37-47, 2007.

FONSECA-KRUEL, V.S.; PEIXOTO, A.L. Etnobotânica na Reserva Extrativista Marinha de Arraial do Cabo, RJ, Brasil. Acta Botanica Brasilica, v.18, n.1, p.177190, 2004.

FREI, B.; BALTISBERGER, M.; STICHER, O.; HEINRICH,

Rev. Bras. PI. Med., Campinas, v.15, n.3, p.442-458, 2013. 
M. Medical ethnobotany of the Zapotecs of the Isthmus-Sierra (Oaxaca, Mexico): Documentation and assessment of indigenous uses. Journal of Ethnopharmacology, v.62, p.149-165, 1998.

GOENKA, A.H. Rustom Jal Vakil and the saga of Rauwolfia serpentina. Journal of Medical Biography, v.15, p.195200, 2007.

GOTTLIEB, O.R.; KAPLAN, M.A.C.; BORIN, M.R.M.B. Biodiversidade: Um enfoque químico-biológico. Rio de Janeiro: Editora UFRJ, 1996.

GUARIM-NETO, G.; MORAIS, R.G. Recursos medicinais de espécies do cerrado de Mato Grosso: um estudo bibliográfico. Acta Botanica Brasilica, v.17, n.4, p.561584, 2003.

GUARIM-NETO, G.; SANTANA, S.R.; SILVA, J.V.B. Notas etnobotânicas de espécies de Sapindaceae Jussieu. Acta Botanica Brasilica, v.14, n.3, p.327-334, 2000.

GUILHERME, D.O.; SANTOS, A.M.; PAULA, T.O.M. ARAUJO, C.B.; SANTOS, W.G.; ROCHA, S.L.; CALDEIRA-JR, C.F.; MARTINS, E.R. Ecogeografia e Etnobotânica da Mangaba (Hancornia speciosa) no Norte de Minas Gerais. Revista Brasileira de Biociências, v.5, n.1, p.414-416, 2007.

ISHARWALL, S.; GUPTA, S. Rustom Jal Vakil: his contributions to cardiology. Texas Heart Institute Journal, v.33, p.161-170, 2006.

JESUS, N.Z.T.; LIMA, J.C.S.; SILVA, R.M.; ESPINOSA, M.M.; MARTINS, D.T.O. Levantamento etnobotânico de plantas popularmente utilizadas como antiúlceras e antiinflamatórias pela comunidade de Pirizal, Nossa Senhora do Livramento-MT, Brasil. Revista Brasileira de Farmacognosia, v.19, n.1A, p.130-139, 2009.

JIN, G.B.; HONG, T.; INOUE, S.; URANO, T.; CHO, S.; OTSU, K.; KITAHARA, Y.; CYONG, J.C. Augmentation of immune cel activity against tumor cells by Rauwolfia radix. Journal of Ethnopharmacology, v.81, p.365372, 2002.

JUDD, W.S.; CAMPBELL, C.S.; KELLOGG, E.A.; STEVENS, P.F.; DONOGHUE, M.J. Sistemática Vegetal: Um Enfoque Filogenético. Tradução André Olmos Simões et al. 3 ed. Porto Alegre: Artmed, 2009. $632 \mathrm{p}$.

KISSMANN, K.; GROTH, D. Plantas Infestantes e Nativas. $2^{a}$ ed. São Paulo: BASF, 1999.

$\mathrm{KOCH}, \mathrm{I}$. Estudos das espécies neotropicais do Gênero Rauvolfia L. (Apocynaceae). 2002. 301p. Tese (Doutorado) - Instituto de Biologia, Universidade Estadual de Campinas, Campinas.

LEITÃO, F.; FONSECA-KRUEL, V.S.; SILVA, I.M.; REINERT, F. Urban ethnobotany in Petrópolis and Nova Friburgo (Rio de Janeiro, Brazil). Brazilian Journal of Pharmacognosy, v.19, n.1B, p.333-342, 2009.

LIMA, A.B.; SILVA, A.M.A.; MEDEIROS, A.N.; RODRIGUES, O.G.; ARAÚJO, G.T.; COSTA, R.G. Estudos preliminares da Calotropis procera S.W. na dieta de ovino. Agropecuária Científica no SemiÁrido, v.1, p.15-24, 2005.

LOPES, J.F. Loimbina e uleína isolados de Himatanthus lancifolius (Muell.-Arg.) Woodson, Apocynaceae. 2008. 79p. Dissertação (Mestrado em Farmácia) Universidade Federal do Paraná, Curitiba.

LORENZI, H. Árvores Brasileiras: Manual de Identificação e Cultivo de Plantas Arbóreas Nativas do Brasil. $2^{a}$ ed.
Novas Odessa: Editora Plantarum, v.1, 1998. 384p. LORENZI, H.; MATOS, F.J.A. Plantas medicinais do Brasil: nativas e exóticas. Nova Odessa: Instituto Plantarum, 2002. 576p.

LORENZI, H.; SOUZA, H.M.S. Plantas ornamentais no Brasil: arbustos, herbáceas e trepadeiras. Nova Odessa, SP: Editora Plantarum, 1995. 1120p.

LUCENA, R.F.P.; ALBUQUERQUE, U.P.; MONTEIRO, J.M.; ALMEIDA, C.F.C.B.R.; FLORENTINO, A.T.N.; FERRAZ, J.S.F. Useful Plants of the Semi-Arid Northeastern Region of Brazil: A Look at their Conservation and Sustainable Use. Environ Monit Assess, v.125, p.281-290, 2007.

MAGALHÃES, A. Perfil etnobotânico e conservacionista das comunidades do entorno da Reserva Natural Serra das Almas, Ceará - Piauí, Brasil. 2006. 81p. Dissertação (Mestrado em Desenvolvimento e Meio Ambiente) - Universidade Federal do Ceará, Fortaleza.

MAIOLI-AZEVEDO, V.; FONSECA-KRUEL, V.S. Plantas medicinais e ritualísticas vendidas em feiras livres no Município do Rio de Janeiro, RJ, Brasil: estudo de caso nas zonas Norte e Sul. Acta Botanica Brasilica, v.21, n.2, p.263-275, 2007.

MASCOLO, N.; SHARMA, R.; JAINB, S.C.; CAPASSO, F. Ethnopharmacology of Calotropis procera flowers. Journal of Ethnopharmacology, v.22, p.211-221, 1988.

MATOS, F.J.A. Plantas da medicina popular do Nordeste. Fortaleza: EUFC, 1999. 80p.

MEDEIROS, M.F.T.; ANDREATA, R.H.P.; VALLE, L.S. Identificação de termos oitocentistas relacionados às plantas medicinais usadas no Mosteiro de São Bento do Rio de Janeiro, Brasil. Acta Botanica Brasilica, v.24, n.3, p.780-789, 2010.

MENEZES, P.R.; SCHWARZ, E.A.; SANTOS, C.A.M. In vitro antioxidant activity of species collected in Paraná. Fitoterapia, v.75, p.398-400, 2004.

MESQUITA, M.L.; DESRIVOT, J.; FOURNET, A.; PAULA, J.E.; GRELLIER, P.; ESPINDOLA, L.S. Antileishmanial and trypanocidal activity of Brazilian Cerrado plants. Memórias do Instituto Oswaldo Cruz, v.100, p.783787, 2005.

METCALFE, C.R.; CHALK, L. Anatomy of the dicotyledons: leaves, stem and wood in relation to taxonomy with notes on economic uses. Claredon Press: Oxford, v.2, 1950.

MIRANDA, A.L.; SILVA, J.R.; REZENDE, C.M.; NEVES, J.S.; PARRINI, S.C.; PINHEIRO, M.L.; CORDEIRO, M.C.; TAMBORINI, E.; PINTO, A.C. Anti-inflammatory and analgesic activities of the latex containing triterpenes from Himatanthus sucuuba. Planta Medica, v.66, p.284-286, 2000.

MORAES, T.M.; RODRIGUES, C.M.; KUSHIMA, H.; BAUAB, T.M.; VILLEGAS, W.; PELLIZZON, C.H.; BRITO, A.; HIRUMA-LIMA, C.A. Hancornia speciosa: Indications of gastroprotective, healing and anti-Helicobacter pylori actions. Journal of Ethnopharmacology, v.120, n.2, p.161-168, 2008.

MORAIS, S.M.; DANTAS, J.D.P.; SILVA, A.R.A.; MAGALHÃES, E.F. Plantas medicinais usadas pelos índios Tapebas do Ceará. Revista Brasileira de Farmacognosia, v.15, n.2, p.169-177, 2005.

MOSCA, V.P.; LOIOLA, M.I.B. Uso popular de plantas

Rev. Bras. PI. Med., Campinas, v.15, n.3, p.442-458, 2013. 
medicinais no Rio Grande do Norte, Nordeste do Brasil. Revista Caatinga, v.22, n.4, p.225-234, 2009.

MOZA, M.K. Forsteronia refracta holds the key to breast cancer treatment. Current Science, v.88, n.8, p.1122, 2005.

NARDIN, J.M.; SOUZA, W.M.; LOPES, J.F.; FLORÃO, A.; SANTOS, C.A.M.; WEFFORT-SANTOS, A.M. Effects of Himatanthus lancifolius on human leukocyte chemotaxis and their adhesion to integrins. Planta Medica, v.74, p.1253-1258, 2009.

NETO, C.C.; OWENS, C.W.; LANGFIELD, R.D.; COMEAU, A.B.; ONGE, J.S.; VAISBER, A.J.; HAMMOND, G.B. Antibacterial activity of some medicinal plants from the Callejon de Huaylas. Journal of Ethnopharmacology, v.79, p.133-138, 2002.

NODARI, R.O.; GUERRA, M.P. Biodiversidade: aspectos biológicos, geográficos, legais e éticos. In: SIMÕES, C.M.O. et al. (eds.). Farmacognosia da planta ao medicamento. Porto Alegre: UFRGS/ UFSC, 1999. p.11-24.

NOELLI, F.S. Múltiplos usos de espécies vegetais pela farmacologia guarani através de informações históricas. Diálogos, v.2, n.177-199, 1998.

NUNES, G.P.; SILVA, M.F.; RESENDE, U.M.; SIQUEIRA, J.M. Plantas medicinais comercializadas por raizeiros no Centro de Campo Grande, Mato Grosso do Sul. Revista Brasileira de Farmacognosia, v.13, n.2, p.83-92, 2003.

OLIVEIRA, E.C.S.; TROVÃO, D.M.B.M. O uso de plantas em rituais de rezas e benzeduras: um olhar sobre esta prática no estado da Paraíba. Revista Brasileira de Biociências, v.7, n.3, p.245-251, 2009.

PASA, M.C.; SOARES, J.J.; GUARIM-NETO, G. Estudo etnobotânico na comunidade de Conceição-Açu (alto da bacia do rio Aricá Açu, MT, Brasil). Acta Botanica Brasilica, v.19, n.2, p.195-207, 2005.

PEREIRA, M.M.; JÁCOME, R.L.R.P.; ALCÂNTARA, A.F.C.; ALVES, R.B.; RASLAN, D.S. Alcalóides indólicos isolados de espécies do gênero Aspidosperma (Apocynaceae). Química Nova, v.30, n.4, p.970-983, 2007.

PESEWU, G.A.; CULTLER, R.R.; HIMBER, D.P. Antibacterial activity of plants used in traditional medicines of Ghana with particular reference to MRSA. Journal of Ethnopharmacology, v.116, p.102-111, 2008.

PIRES, M.V.; ABREU, P.P.; SOARES, C.S.; SOUZA, B.; MARIANO, D.; SILVA, D.C.; ROCHA, E.A. Etnobotânica de terreiros de candomblé nos municípios de llhéus e Itabuna, Bahia, Brasil. Revista Brasileira de Biociências, v.7, n.1, p.3-8, 2009.

QUINET, C.G.P.; ANDREATA, R.H.P. Estudo taxonômico e morfológico das espécies de Apocynaceae Adans. na reserva Rio das Pedras, município de Mangaratiba, Rio de Janeiro, Brasil. São Leopoldo: Instituto Anchietano de Pesquisas, Pesquisas, Botânica, n.56, p.13-74, 2005. QUINTANS-JÚNIOR, L.J.; ALMEIDA, J.R.G.S.; LIMA, J.T.; NUNES, X.P.; SIQUEIRA, J.S.; OLIVEIRA, L.E.G.; ALMEIDA, R.N.; ATHAYDE-FILHO, P.F.; BARBOSAFILHO, J.M. Plants with anticonsvulsant properties-a review. Revista Brasileira de Farmacognosia, v.18, p.798-819, 2008.

QUINTANS-JÚNIOR, L.J.; SILVA, D.A.; SIQUEIRA, J.S.; SOUZA, M.F.V.; BARBOSA-FILHO, J.M.; ALMEIDA,
R.N.; SILVA-JÚNIOR, R.G.C. Anticonvulsant properties of the total alkaloid fraction of Rauvolfia ligustrina Roem. et Schult. in male mice. Revista Brasileira de Farmacognosia, v.17, p.152-158, 2007.

QUINTANS-JÚNIOR, L.J.; SIQUEIRA, J.S.; MELO, M.S.; SILVA, D.A.; MORAIS, L.C.S.L.; SOUZA, M.F.V.; ALMEIDA, R.N. Anticonvulsant evaluation of Rauvolfia ligustrina Willd. ex Roem. \& Schult., Apocynaceae, in rodents. Brazilian Journal of Pharmacognosy, v.20, n.1, p.54-59, 2010.

RAPINI, A.; KOCK, I.; KINOSHITA, L.S.; SIMÕES, A.O.; SPINA, A.P. Apocynaceae. In: FORZZA; R.C. et al. (Org.). Catálago de plantas e fungos do Brasil. Jardim Botânico do Rio de Janeiro, v.1, p.617-644, 2010.

RECH, S.B.; BATISTA, C.V.F.; SCHRIPSEMA, J.; VERPOORTE, R.; HENRIQUES, A.T. Cell cultures of Rauwolfia sellowi: grawth and alkaloid production. Plant Cell Tiss Org, v.54, p.61-63, 1998.

RITTER, M.R.; SOBIERAJSKI, G.R.; SCHENKEL, E.P.; MENTZ, L.A. Plantas usadas como medicinais no município de Ipê, ES, Brasil. Revista Brasileira de Farmacognosia, v.12, p.51-62, 2002.

RIZZINI, C.T.; MORS, W.B. Botânica econômica brasileira. 2 ed. Rio de Janeiro: Âmbito Cultural, 1995. 248p.

RODRIGUES, E.; DUARTE-ALMEIDA, J.M.; PIRES, J.M. Perfil farmacológico e fitoquímico de plantas indicadas pelos caboclos do Parque Nacional do Jaú (AM) como potenciais analgésicas. Parte I. Revista Brasileira de Farmacognosia, v.20, n.2, 2010.

RODRIGUES, V.E.G.; CARVALHO, D.A. Levantamento etnobotânico de plantas medicinais no domínio do cerrado na região do Alto Rio Grande - Minas Gerais. Ciência e Agrotecnologia, v.25, n.1, p.102-123, 2001.

SAMPAIO, T.S.; NOGUEIRA, P.C.L. Volatile components of mangaba fruit (Hancornia speciosa Gomes) at three stages of maturity. Food Chemistry, v.95, n.4, p.606610, 2006.

SANTOS, A.K.L.; MAGALHÃES, T.S.; MONTE, F.J.Q.; MATTOS, M.C.; OLIVEIRA, M.C.F.; ALMEIDA, M.M.B.; LEMOS, T.L.G.; BRAZ-FILHO, R. Alcalóides iboga de Peschiera affinis (Apocynaceae) - atribuição inequívoca dos deslocamentos químicos dos átomos de hidrogênio e carbono. Atividade antioxidante. Química Nova, v.32, n.7, p.1834-1838, 2009.

SCHRIPSEMA, J. GAGNINO, D.; GOSMANN, G. Alcalóides Indólicos. In: SIMÕES, C.M.O.; SCHENKEL, E.P.; GOSMANN, G.; MELLO, J.C.P.; MENTZ, L.A.; PETROCICK, P.R. (Orgs.). Farmacognosia: da planta ao medicamento. Porto Alegre/Florianópolis: UFRGS/ UFSC, 2004. p.819-846.

SERRA, C.P.; CÔRTES, S.F.; LOMARDI, J.A.; BRAGADE-OLVEIRA, A.; BRAGA, F.C. Validation of a colorimetric assay for the vitro screening of inhibitors of Angiotensis-Converting Enzyme (ACE) from plant extracts. Phytomedicine, v.12, n.6-7, p.424-432, 2005.

SILVA, A.C.O.; ALBUQUERQUE, U.P. Woody medicinal plants of the caatinga in the state of Pernambuco (Northeast Brazil). Acta Botanica Brasilica, v.19, n.1, p.17-26, 2005.

SILVA, A.J.R.; ANDRADE, L.H.C. Etnobotânica nordestina: estudo comparativo da relação entre comunidades e vegetação na Zona do Litoral - Mata do Estado de

Rev. Bras. PI. Med., Campinas, v.15, n.3, p.442-458, 2013. 
Pernambuco, Brasil. Acta Botanica Brasilica, v.19, n.1, p.45-60, 2005.

SILVA, C.S.P.; PROENÇA, C.E.B. Uso e disponibilidade de recursos medicinais no município de Ouro Verde de Goiás, GO, Brasil. Acta Botanica Brasilica, v.22, n.2, p.481-492, 2008.

SILVA, G.L.C.; GAERTNER, P.; MARSON, P.G.; SCHWARZ, E.A.; SANTOS, C.A.M. An ethnopharmacobotanical survey in Salto Caxias Hydroelectric Power Plant in Paraná State, Brasil, before the flooding. Acta Farmaceutica Bonaerense, v.23, p.148-153, 2004.

SILVA, J.M.; FRANCO, E.S. Florística de espécies arbórea-arbustivas do sub-bosque com potencial fitoterápico em fragmento florestal urbano no município de Camaragibe, Pernambuco, Brasil. Caminhos de Geografia, v.11, n.35, p.179-194, 2010.

SILVA, J.P.A.; SAMPAIO, L.S.; OLIVEIRA, L.S.; REIS, L.A. Plantas medicinais utilizadas por portadores de diabetes mellitus tipo 2 para provável controle glicêmico no município de Jequié-BA. Revista Saúde.com, v.4, n.1, p.10-18, 2008.

SOARES, C.M.; ENDRINGER, D.C.; CAMPANA, P.V.; VALADARES, Y.M.; BRAGA, F.C. Estudo fitoquímico de Hancornia speciosa Gomes biomonitorado por ensaio in vitro de atividade inibitória da Enzima Conversora da Angiotensina (ECA). In: XIX SIMPÓSIO DE PLANTAS MEDICINAIS DO BRASIL, 2006, Salvador-BA, Anais... Salvador, 2006.

SOUZA, C.D.; FELFILI, J.M. Uso de plantas medicinais na região de Alto Paraíso de Goiás, GO, Brasil. Acta Botanica Brasilica, v.20, n.1, p.135-142, 2006.

SOUZA, V.C.; LORENZI, H. Botânica Sistemática: guia de ilustrado para identificação das famílias de Fanerógamas nativas e exóticas no Brasil, baseado em APG II. 2 ed. São Paulo: Instituto Plantarum, 2008. 704p.

SOUZA, W.M.; STINGHEN, A.E.; SANTOS, C.A. Antimicrobial activity of alkaloidal fraction from barks of Himatanthus lancifolius. Fitoterapia, v.75, p.750-753, 2004.

SOUZA-FAGUNDES, E.M.; QUEIROZ, A.B.R.; MARTINSFILHO, O.A.; GAZZINELLI, G.; CORREA-OLIVEIRA, R.; ALVES, T.M.A.; ZANI, C.L. Screening and fractionation of plant extracts with antiproliferative activity on human peripheral blood mononuclear cells. Memórias do Instituto Oswaldo Cruz, v.97, p.1207-1212, 2002.

TANAKA, J.C.A.; SILVA, C.C.; OLIVEIRA, A.J.B.; NAKAMURA, C.V.; DIAS-FILHO, B.P. Antibacterial activity of indole alkaloids from Aspidosperma ramiflorum. Brazilian Journal of Medical and Biological Research, v.39, p.387-391, 2006.

TEIXEIRA, S.A.; MELO, J.I.M. Plantas medicinais utilizadas no município de Jupi, Pernambuco, Brasil. Iheringia, v.61, n.1-2, p.5-11, 2006.

TONA, L.; KAMBU, K.; NGIMBI, N.; CIMANGA, K.; VLIETINCK, A.J. Antiamoebic and phytochemical screening of some Congose medicinal plants. Journal of Ethnopharmacology, v.61, p.57-65, 1998.

TONA, L.; KAMBU, K.; NGIMBI, N.; CIMANGA, K.; VLIETINCK, A.J. Antiamoebic and phytochemical screening of some Congose medicinal plants. Journal of Ethnopharmacology, v.61, p.57-65, 1998.

VILLEGAS, L.F.; FERNANDEZ, I.D.; MALDONADO, H.; TORRES, R.; ZAVALETA, A.; VAISBERG, A.J.; HAMMNOND, G.B. Evalution of the wound-healing activity of selected traditional medicinal plants from Peru. Journal of Ethnopharmacology, v.55, p.193200, 1997.

WACHSMUTH, O.; MATUSCH, R. Anhydronium bases from Rauvolfia serpentina. Phytochemistry, v.61, p.705-709, 2002.

WOOD, C.A.; LEE, K.; VAISBERG, A.J.; KINGSTON, D.G.; NETO, C.C.; HAMMOND, G.B. A bioactive spirolactone iridoid and triterpenoids from Himatanthus sucuuba. Chemical \& Pharmaceutical Bulletin, v.49, p.14771478, 2001.

YODER, L.R.; MAHLBERG, P.G. Reactions of alkaloid and histochemical indicators in laticifers and specialized parenchyma cells of Catharanthus roseus (Apocynaceae). American Journal of Botany, v.63, p.1167-1173, 1976.

ZUCHIWSCHI, E.; FANTINI, A.C.; ALVES, A.C.; PERONI, N. Limitações ao uso de espécies florestais nativas pode contribuir com a erosão do conhecimento ecológico tradicional e local de agricultores familiares. Acta Botanica Brasilica, v.24, n.1, p.270-282, 2010. 